\title{
Weathering Economic Shocks and Financial Uncertainty: Here We Go Again
}

\author{
Joyce Serido ${ }^{1}$
}

Published online: 3 August 2020

(c) Springer Science+Business Media, LLC, part of Springer Nature 2020

In the early spring of 2020, there were a lot of comparisons being drawn between the Great Recession and the COVID19 pandemic. What they have in common is the capacity for major disruption to people's financial lives, introducing conflict, strain, and adaptation. There is an important difference between the two events: whereas financial imbalances, notably in the US housing market, precipitated the global economic meltdown and protracted recovery, the novel coronavirus ushered in a worldwide Mr. Toad's Wild Ride of unpredictable economic, social, and political change. It provides a fertile environment for examining the connections between economic uncertainty and family functioning.

The articles selected for this issue cover a wide range of topics that affect household stability: relationships, housing, nutrition, health, and wealth. Many of the articles rely on national samples in the United States and around the globe, while others focus on the economic interactions within the family. Each of the articles offers insights for researchers who seek to understand the impact of economic uncertainty in people's everyday lives and for practitioners looking for ways to help people adapt to change and uncertainty.

\section{Couples and Finances}

The first three articles consider the impact of finances on couples' well-being. Morgan and Lim (2020) examine the bidirectional longitudinal associations of financial conflict and depression using a national longitudinal study of German couples. They provide evidence of a bidirectional effect over time, as well as some differences in the effects for men and women. The study by Addo and Zhang (2020) highlight the importance of obtaining data from each partner in addition to objective indicators of financial circumstances. In

Joyce Serido

jfei.editor.js@gmail.com

1 University of Minnesota-Twin Cities, Saint Paul, MN, USA this study the researchers examine what each partner knows about their current debt as well as how they manage their finances to understand how debt affects relationship quality. In a study of primarily lower-income unmarried couples with children, LeBaron et al. (2020) find support that financial stressors may promote relational growth, and that positive perceptions regarding the relationship, in addition to the financial situation, play an important part in relational bonadaptation. Overall, these studies highlight the need for multi-informant research to disentangle the effects of economic issues on both the household and the individual family members. Although increasing income may not be possible, practitioners may assist couples in reducing relationship strain by providing information and access to financial support networks and coaching them in talking about financial topics.

\section{Domains of Household Financial Management}

The next set of articles examine the impact of financial strain in specific household domains. Grafova, Monheit, and Kumar examine the effect of economic shocks on the out-of-pocket health care spending burden for both singlemother and two-parent families using pooled 2-year panel data (2004-2012). They find that families maintain both out-of-pocket and total health care spending in the short term, even though it represents a greater share of the family income. This raises important questions about families' ability to withstand further financial strain with the growing number of COVID-19 cases and associated financial burden of treatment.

Delayed homeownership among young adults in the US is of concern, both as an indicator of wealth and as a generational change in values. In examining foreclosure on parental homes following the Great Recession, Xu (2020) finds that homeownership rates are lower for young adults who 
experienced parental foreclosure. Interestingly, it appears that the psychological effects on the young adults, rather than economic shocks or parental financial transfers, account for the difference.

Dwyer Emory et al. (2020) provide insights on the role of economic stability for fathers' residence and custody arrangements, finding that fathers in minimum-wage jobs were more likely to live with their children as the minimum wage increased but less likely to live with their children when mothers in minimum wage jobs saw wage increases.

Government-provided food assistance plays an important role in helping families remain food-secure, and eligibility for benefits requires accurate measures. Tanaka, Engelhard, and Rabbit (2020) assess the reliability of the Household Food Security Survey Module (HFSSM), a unidimensional tool used to determine access to benefits in the US and a model for several countries. Because the HFSSM includes both adultreferenced and child-referenced items, the researchers tested the validity of the measure as a multidimensional scale. Their analyses confirm that the current unidimensional measure is appropriate for measuring food-insecurity.

\section{Finances and Life Choices}

The next three articles provide insights on factors that may influence the choices people make in allocating available resources. With an increasingly aging population worldwide, ensuring that families have adequate financial resources for later life is of growing concern. Yet, future uncertainty plays a role in the investment decisions. Domeniko and Verbič (2020) consider the role that quality of life plays in stock market investing among older adults across 13 European countries. Overall, they find that higher levels of quality of life are associated with more stock market investing, however, risk aversion, more so than trust, is an important mediating factor in the decision-making process.

Although limited finances are an important factor in the life choices people make, time constraints are also important. In the study by Urakawa, Wang, and Alam (2020), the effects of both income and time poverty influence daily health activities, but in different ways. Using a national sample of adults in Japan, the researchers find that income poverty is associated with less physical activity whereas time poverty is associated with less sleep. These findings raise interesting questions during the pandemic when the demands of many workers have increased (time poverty) at the same time as many others have been furloughed or laid off (income poverty).

Additional insights on the tradeoff between finances and time in making life choices come from a study by Barardehi, Babiarz, and Mauldin (2020). On the associations between child support on consumption and employment in single mother families and using data from the Panel Study of Income
Dynamics (1999-2013), the researchers find that the receipt of child support by single mothers does not result in improved material well-being (i.e. increased consumption), and in fact leads to a decline in work engagement. The findings suggest that single-mothers may prefer free time over consumption.

\section{Financial Literacy and Financial Stability}

The last three papers in this issue inform our understanding of antecedents of financial literacy and financial stability. Emergency savings are a sign of financial preparedness and stability, and the article by Despard, Friedline, and West (2020) adds to our understanding of factors that promote emergency savings, even during economic shocks. Using national survey data (NFCS 2009, 2012, 2015 and 2018), the researchers show that three factors (subjective knowledge, financial confidence, and having a saving account) are important antecedents of emergency savings, across all income groups. In contrast, the effect of higher objective financial knowledge was not sufficient to withstand the effects of the economic downturn on the saving behaviors of low- and moderate-income households. AlBahrani, Buser, and Patel (2020) examine math ability as a possible explanation for the gap in financial literacy between men and women in a sample of college students. Measured as both subjective (perceived) and objective (quiz results) math ability, they find that objective math ability predicts financial literacy for men, whereas subjective math ability predicts financial literacy for women. In the final article in this issue, Ali, Kahn and Ahmed (2020) add a cultural context to the impact of economic shocks, by including household valuables (e.g., gold, silver, precious stones) in addition to real estate and financial assets, in examining financial stability of Pakastani households. They find that household valuables contribute to financial stability by lowering the debt-to-asset ratio (DAR) making it more likely that households are able to withstand economic shocks.

\section{Concluding Remarks}

Although every macro-economic shock is uniquely situated in historic time, the impact on the everyday lives of people continues to play out in familiar household domains: health care, housing, employment, and food. The articles in this issue remind us to look for insights from previous research in investigating the impact of the Covid-19 pandemic.

Publisher's Note Springer Nature remains neutral with regard to jurisdictional claims in published maps and institutional affiliations. 